\title{
Control of energy aspects of track and rolling stock interaction
}

\author{
Victor Pevzner ${ }^{1, *}$, Uriy Romen ${ }^{1}$, and Kirill Shapetko ${ }^{1}$ \\ 1 JSC “VNIIZhT" (Railway Research Institute), Moscow, 129626, Russia
}

\begin{abstract}
The paper analyses international practices of energy saving for train traction. It describes methods that allow decrease of power consumption. Russian practices of energy consumption for train traction are reviewed, as well as methods for determining the power consumption related to condition of track layout geometry. Best practices of evaluation of impact of profile elevation unevenness to the train traction energy consumption are presented. The calculations that allow matching the data on track geometry before and after track maintenance works are performed, and the convictions concerning cost reduction for train traction energy saving are developed.
\end{abstract}

\section{Introduction}

Analysis of international practices shows that the problem of energy efficiency enhancement on railway transport is of great current interest and much prominence is given to it. Train traction energy consumption is one of the main expenditures for the traffic performance. Optimization of these expenditures requires analysis of all the factors that compose the running resistance [1]. Researches carried out on the railways in Europe [2-4] indicated significance of cost reduction for train traction energy consumption. In the researches [4,5] there was highlighted the issue of appreciation of electric energy due to the energy sources cost increase. In the view of increase of energy consumption during the peak hours, the complex methods of limitation of peak load by manipulations on train driving methods were presented. It was noted in the research [6], that automatic train operation systems developed in Germany enable to cut energy loss by $15 \%$. Data obtained by the German railway alliance Allianz pro Schiene "Fahr umweltbewusst!" [7] confirms that the driver assistance systems are necessary tools for lowering of energy consumption by train driving. The research [8] analyses cut of energy consumption by means of reduction of weight of the rolling stock. I is noted, that reduction of weight by $10 \%$ results in lowering of energy consumption by $1 \%$ and significant decrease of operational costs.

These methods are based in general on economical driving and reduction of train weight, but this cannot serve as the full picture of train traction energy consumption, especially against the background of broad introduction of trains of increased weight and higher axle loads of freight cars. Nowadays it is necessary to take into account additional methods of energy consumption control, that can be based, for instance, on the wheel-rail interaction and impact of parameters of track geometry layout [9] on train traction.

* Corresponding author: vpevzner@list.ru 


\section{Research materials and methods}

In the 1950's professor M.F. Verigo pointed out, that the core running resistance to be evaluated by the sum of energy dissipation in the systems as follows:

- resistance resulting from dissipation of energy on the way (under its interaction with the rolling stock);

- resistance resulting from force processes in the wheel-rail system;

- resistance resulting from dissipation of energy to the environment (in the dampers and other friction joints).

As the energy dissipation on the way is related to the development of residual deformation in it, application of the energy method will allow evaluation of interaction of the carriages on the track from the viewpoint of development of residual deformation.

Researches on the aggregated work of lateral and longitudinal forces of pseudo-sliding on the contact surface that determine by multiplication of these forces by the distance that is covered by the carriage with regard to its lateral oscillations, showed that energy count as a result of oscillating process of carriage of the rolling stock sufficiently studied and can be mathematically modelled.

During mathematical modelling of interacting processes energy dissipation value to be determined for all the dissipative forces on every step of calculation, followed by their summing up within the whole considered track section.

The calculation is to be made on every step $\Delta t$ of digital calculation method. Initial point of a step is $t_{m}$, the final pint of a step is $t_{m}+1=t_{m}+\Delta t$. When calculating along the track, the relative shifts edge points of the considered elements, for which the elementary work is calculated, are $S_{m}$ и $S_{m+l}$, and the calculating step on the track is $\Delta S=V \Delta t$.

Energy dissipation $A_{m}$ in a suspension of three-element bogie of 18-100 type during vertical oscillations of a carriage for one calculation step $\Delta S$ that corresponds the time step $\Delta t=t_{m}+1-t_{m}$ to be calculated according to the formula (1):

$$
\begin{aligned}
A_{m}\left(F_{z}\right)=\sum_{j k} A_{m} & {\left[F_{z m}\left(\Delta_{j k}^{* \prime}\right)\right] } \\
= & \sum_{j k}\left|\left[\Delta_{j k}^{*}\left(t_{m+1}\right)-\Delta_{j k}^{*}\left(t_{m}\right)\right]\right| \\
\cdot & {\left[\left|\varphi_{z}\left(\Delta N_{j k b}^{*}++\Delta N_{j k T}^{*}\right) F_{F z}\right|+\left|k^{* \prime} V_{j k}^{* \prime}\right|\right] }
\end{aligned}
$$

$F_{z m}\left(\Delta_{j k}^{* \prime}\right)$ is a value of friction force on a given calculation step $(m+1)$;

$\Delta_{j k}^{*}\left(t_{m+1}\right)-\Delta_{j k}^{*}\left(t_{m}\right)$ is a distance by connecting pin displacement vertically towards the friction plate for given calculation step, where friction force and the value of relative displacement should be determined along with the algorithm of data calculation described by P.N. Astakhov.

Energy dissipation in a spring arrangement by carriage oscillation (horizontal movements of connecting pins) are determined as well with regard to the value of lateral displacement of a side bogie frame towards truck bolster for a calculation step $t_{m+1}-t_{m}$ :

$$
A_{m}\left(F_{Y}\right)=\sum_{j k}\left[\left|k^{*} V \Delta_{y j k}^{\prime}\right|+\left|\bar{F}_{Y}+\left(\Delta_{y j k}^{\prime}\right)\right|\right] \cdot\left|\Delta_{y j k}\left(t_{m+1}\right)-\Delta_{y j k}\left(t_{m}\right)\right|
$$

The calculation is the same for energy loss in all places of contact of the elements of the design. 
The calculations showed that energy losses because for the friction in the elements of undercarriage and wheel-rail system with no regard for friction axle bearings amount to $25 \ldots 30 \%$ of all total energy loss for traction.

To illustrate the impact of track condition on energy dissipation in different elements of a car-track system, Fig. 1 demonstrates the results of calculations, derived from two straight track sections of different conditions. The graph demonstrates the losses for vertical friction in a wedge system of spring suspension (value $A(F z)$ ). Value $A(H)$ signifies losses from sliding in wheel-rail head system; $\Sigma A$ is a total energy loss.

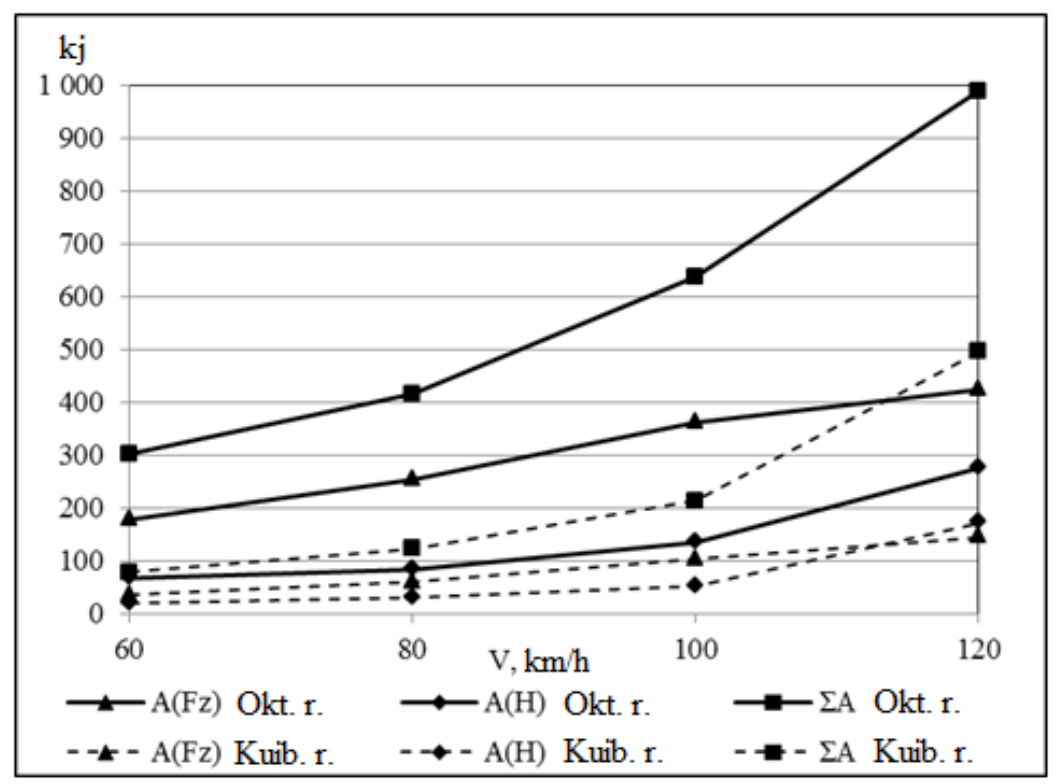

Fig. 1. Calculated energy losses for friction in undercarriage on straight sections of railway tracks.

It should be mentioned, that traffic performance if influenced by dynamic process in the rolling stock, generated not only by the amplitude of the unevennesses, but also by their location, especially in the zones where speeds are close to the starting point of stability loss and wobbling development. In this case values of unevenness match by deviations and differ only by the form and their combinations. This impact on the values of undercarriage and, as a result, on the intensity of traffic resistance. By speeds up to $60 \mathrm{~km} / \mathrm{h}$ deviations in energy losses by different traffic directions amounted up to $5 \%$, and in a zone of the initial point of intensive wobbling (by moving straightly on the sped up to $120 \mathrm{~km} / \mathrm{h}$ ) exceeded $25 \%$. For illustration, similar to Fig. 1, Fig. 2 demonstrates energy dissipation in different elements of design, where the value $A(F z)$ signifies the losses for the vertical friction in the wedge system, and $A(F y)$ is the losses by the lateral movements in damping system. $A(H)$ signifies the losses for friction sliding in a wheel-rail head system , $A(N)$ is a dissipation in track structure, $\Sigma A$ is an overall loss of energy in the undercarriage.

The conducted researches [10] revealed that in order to reduce energy consumption for train traction a transfer to the new quality level of maintenance of the track layout, that would comply not only traffic safety requirements, but also strict compliance to the design parameters of track geometry along the entire length. Improvement of track conditions, which is a requirement to the energy consumption reduction, demands track control and surfacing systems of a new quality level, that can provide implementation and maintenance in design conditions. 


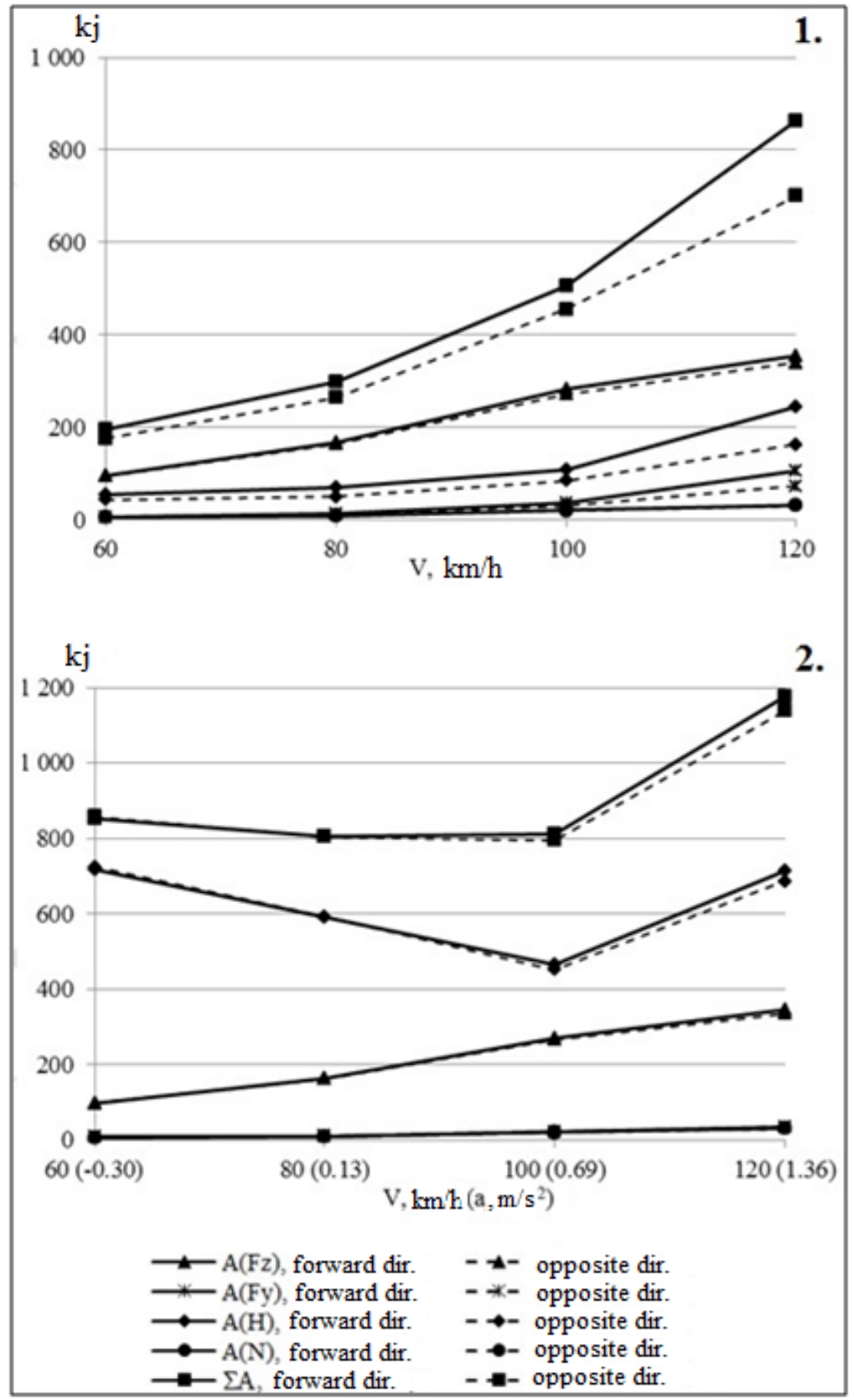

Fig. 2. Impact of combination of track unevennesses (traffic directions) to the energy dissipation during car moving: 1 . on a straight section; 2 . in a curve $\mathrm{R}=500 \mathrm{~m}$ and $\mathrm{h}=140 \mathrm{~mm}$.

Dependence of train traction energy consumption from condition of track plan can be described by the following formula (3):

$$
A=25.2+1.66 \sigma_{p}
$$

where $A$ is energy consumption, kWh;

$\sigma_{\mathrm{p}}$ is a standard deviation of the track location, $\mathrm{mm}$ 
In respect to evaluation of traffic resistance, as an additional factor the long unevennesses in profile of the track and steepness of microslopes of these unevennesses should be taken into account. [11].

\section{Results}

In 2016 on a trial track section a series of tests took place for evaluation of impact of unevennesses of profile elevation to the train traction energy consumption. It was an experimental evaluation of impact of track maintenance to the track traction energy consumption. Energy consumption was measured on a straight section with a freight train on it weighing $6000-6500 \mathrm{t}$ and propelled by the electric locomotive VL80S. There have been made 10 rides before and after capital repairs. Along with that geodesic survey of profile elevation has been made. Also some additional data on profile elevation have been derived with the use of restoring by a special transitional program of the results of the ride of the track recording car of KVL-P type.

Analysis of the results showed that average energy losses of the rides before the maintenance works amounted to $500.4 \mathrm{kWh}$ or $79.9 \mathrm{kWh} / 1000 \mathrm{t}$, and after maintenance works finalizing, on conditions of the similar treatment - to $455.6 \mathrm{kWh}$ or $73 \mathrm{kWh} / 1000 \mathrm{t}$. Consequently, energy consumption reduction amounted to $8.7 \%$.

Quantitative evaluation of unevennesses rate having the length up to $30 \mathrm{~m}$ after the maintenance works steadily decreases, herewith number of unevenesses less than $30 \mathrm{~m}$ long and more remained the same, and their rate increased (Fig. 3).

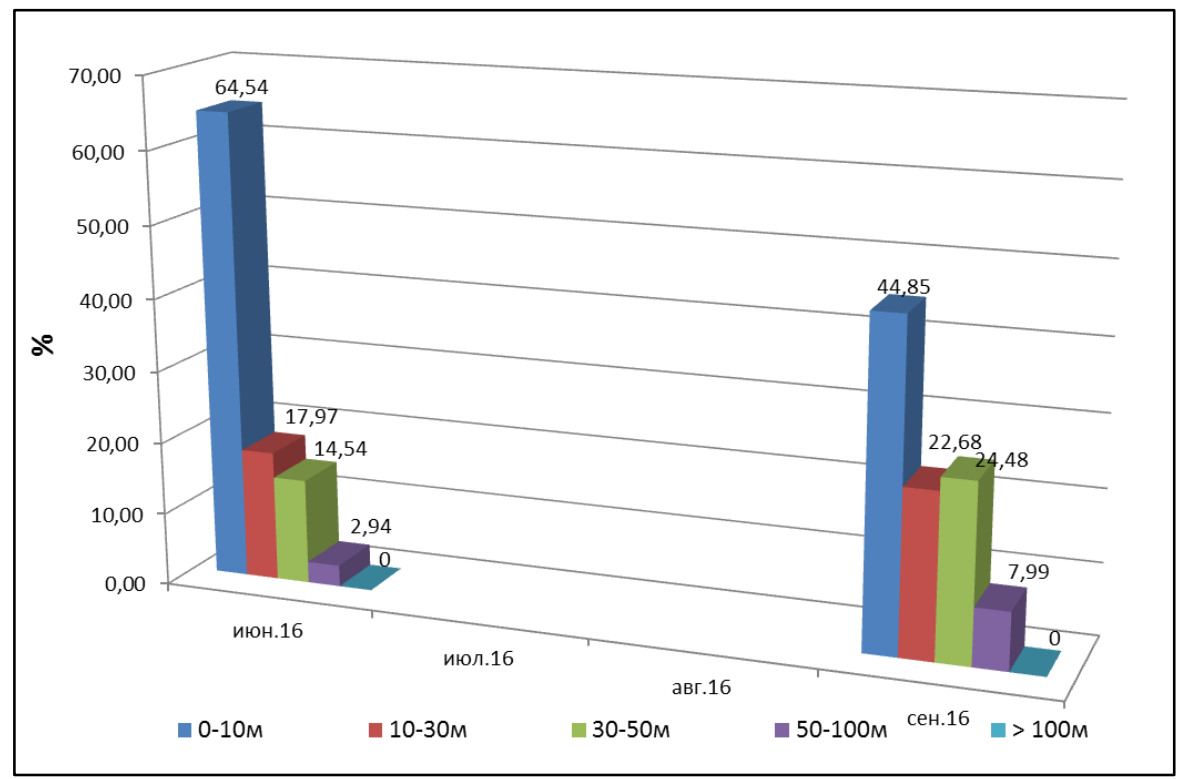

Fig. 3. Quantitative analysis of unevennesses rate lengthwise.

Analysis of total squares of unevennesses presented on Fig. 4 showed, that after the maintenance works total number of unevennesses amounted to $78.3 \%$ of the initial one.

Analysis of standard deviation of the amplitudes of the unevennesses, get from the data collected by the geometry car, revealed that after the maintenance works the standard deviation value reduced from $9.96 \mathrm{~mm}$ to $7.36 \mathrm{~mm}$, i.e., after the maintenance works it amounts to $74.2 \%$ from the values before the maintenance. 


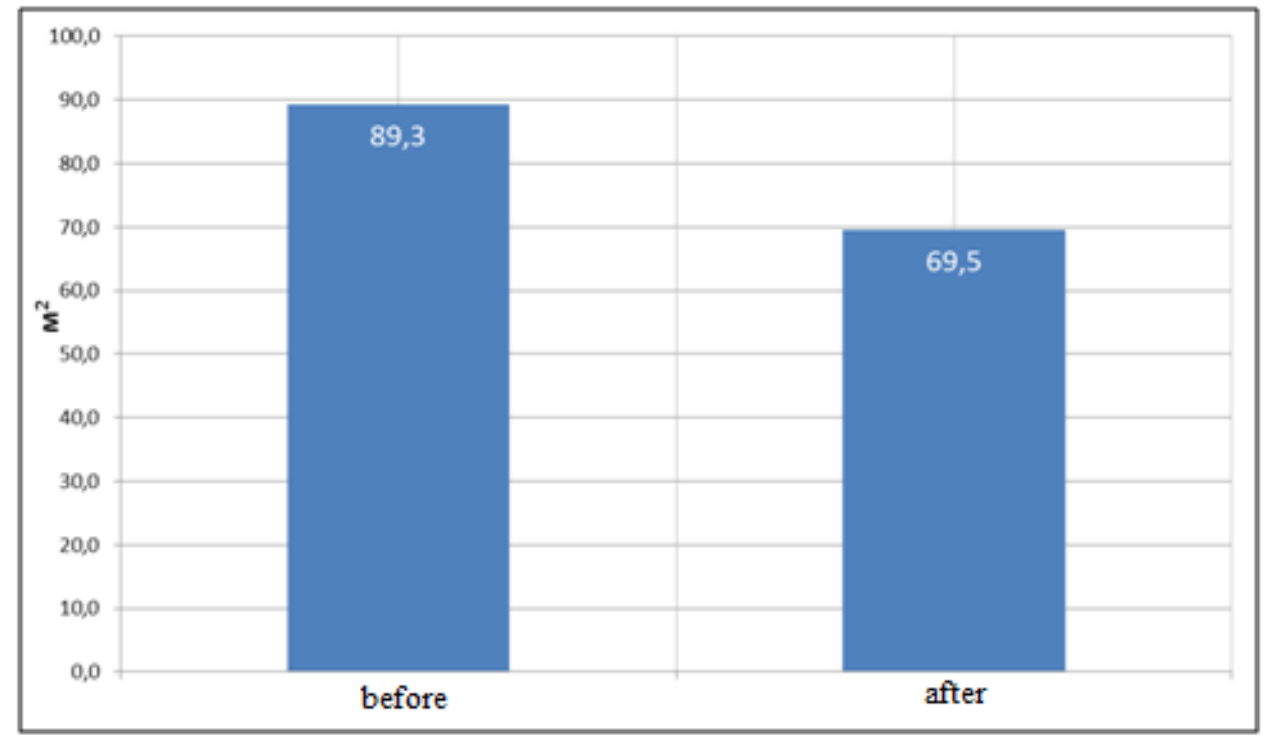

Fig. 4. Analysis is unevennesses squares before and after maintenance works.

According to the results of leveling (without the load) the standard deviation value reduced from $26.51 \mathrm{~mm}$ to $25.14 \mathrm{~mm}$, i.e. amounted to $94.5 \%$ from the initial.

\section{Conclusions}

Therefore, the conducted research allows confirming that the maintenance works helped to reduce the train traction energy consumption by $8.7 \%$ owing to improvement of track condition. I should be noted, that in the course of works some profile unevennesses have been eliminated, which resulted into significant reduction of energy cost.

This confirms that it is possible to regulate the train traction energy consumption volumes by means of application of technical facilities conditions control systems that determine traffic resistance volumes.

\section{References}

1. S. Schranil, Eisenbahn Österreich 8, 396-399 (2017)

2. P. Henry, Revue Générale des Chemins de Fer. 263(9), 34-41 (2016)

3. P. Ho-negger, R. Kögel, N. Hohenbichler, ZEVrail S-H, 18-25 (2016)

4. N. Biedermann, Elektrische Bahnen, 1-12 (2017)

5. Y. Fidansoy, S. Wanjani, Der Eisenbahningenieur 2, $42-44$ (2017)

6. Allianz pro Schiene startet Projekt zu Fahrerassistenzsystemen, Deine Bahn 6, 4 (2017)

7. T. Breustedt, Deine Bahn 10, 28-34 (2017)

8. D. Wimmer, International Railway Journal 6, 42-43 (2017)

9. K.V. Shapet'ko,Vestnik VNIIZhT 76-4, 238-242 (2017)

10. V. Pevzner Railway transport 2-96, 46-49 (2016)

11. V. Kamensky. Directions of improvement of the track management system. (JSC «NIITKD», 2009) 